ARTICLE

https://doi.org/10.1038/s41467-019-08669-1

\title{
Photoredox-catalyzed branch-selective pyridylation of alkenes for the expedient synthesis of Triprolidine
}

Shengqing Zhu', Jian Qin ${ }^{1}$, Fang Wang ${ }^{1}$, Huan $\mathrm{Li}^{1}$ \& Lingling Chu (i) ${ }^{1}$

\begin{abstract}
Alkenylpyridines are important pharmaceutical cores as well as versatile building blocks in organic synthesis. Heck reaction represents one of the most powerful platform for the construction of aryl-substituted alkenes, nevertheless, examples for Heck type coupling of alkenes with pyridines, particularly with branched selectivity, remain elusive. Here we report a catalytic, branch-selective pyridylation of alkenes via a sulfinate assisted photoredox catalysis. This reaction proceeds through a sequential radical addition/coupling/elimination, by utilizing readily available sodium sulfinates as reusable radical precursors as well as traceless elimination groups. This versatile protocol allows for the installation of important vinylpyridines with complete branched selectivity under mild conditions. Furthermore, this catalytic manifold is successfully applied to the expedient synthesis of Triprolidine.
\end{abstract}

\footnotetext{
${ }^{1}$ State Key Laboratory for Modification of Chemical Fibers and Polymer Materials, Center for Advanced Low-Dimension Materials, College of Chemistry, Chemical Engineering and Biotechnology, Donghua University, 201620 Shanghai, China. Correspondence and requests for materials should be addressed to L.C. (email: lingling.chu1@dhu.edu.cn)
} 
yridine is recognized as one of the most important heterocycles in pharmaceuticals, agrochemicals, and bioactive natural products ${ }^{1,2}$. Alkenylpyridines, an important subunit of pyridines, also serve as versatile synthetic building blocks for complex pyridines ${ }^{3,4}$, as well as important ligand scaffolds in the area of catalysis (Fig. 1a) ${ }^{5}$. As a result, the efficient and selective assembly of alkenylpyridines from readily available starting materials has drawn intensive attentions of chemists ${ }^{6-10}$.

Alkenes are one of the most ubiquitous material in organic synthesis. The cross-coupling of alkenes and aryl halides in the presence of palladium catalyst, the Heck reaction ${ }^{11-13}$, is a powerful protocol for the construction of aryl-substituted alkenes. Nevertheless, there are few examples of Heck coupling of alkenes with pyridines, probably due to the potential coordination between the nitrogen atom and metal catalyst ${ }^{14-19}$. Alternatively, several examples of Pd-catalyzed cross-coupling of alkenes with pyridine $\mathrm{N}$-oxides have been reported, while only delivering vinylpyridine derivatives with linear selectivity ${ }^{20-23}$. To the best of our knowledge, catalytic alkene-pyridine couplings with branch selectivity, the control of which remains a big challenge in Heck couplings ${ }^{24-26}$, is unknown.

Recently, radical-based chemistry provides an alternative platform to address this challenge. Particularly, the groups of MacMillan, Jui, and others ${ }^{27-46}$ have successfully demonstrated that visible light photocatalyzed cross-couplings of pyridines to access to alkylated pyridines under mild conditions, by taking advantage of unique reactivity of open-shell pyridyl radical species (Fig. 1b). While significant advances, no examples of vinylation of pyridines via pyridyl radical species has been reported. Herein, we demonstrate an alternative protocol, through a sequential radical addition/radical coupling/elimination pathway, to access vinylpyridines from readily available alkenes with complete branch selectivity (Fig. 1c). This reaction takes advantage of a synergistic combination of visible light-induced photoredox catalysis and a catalytic radical precursor, providing an effective and selective strategy for the synthesis of a-vinylpyridines under mild conditions.

\section{Results}

Design plan. We hypothesized that sodium sulfinates would be the ideal reusable radical precursors, due to the unique properties of which: (i) sufinates have been recently employed as efficient sulfonyl coupling partners in photoredox catalysis ${ }^{47-62}$; (ii) it is well known that the alkyl sulfones would be prone to undergo desulfonylation under basic conditions ${ }^{63-65}$. As depicted in Fig. 2, we envisioned that a single-electron reduction between photoexcited
${ }^{*} \operatorname{Ir}(\mathrm{ppy})_{3} 2\left\{E_{1 / 2}{ }^{\text {red }}\left[{ }^{*} \mathrm{Ir}^{\mathrm{III}} / \mathrm{Ir}^{\mathrm{IV}}\right]=-1.73 \mathrm{~V} \text { vs. SCE }\right\}^{66}$ and cyanopyridine $3\left(E_{1 / 2} \text { red }=-1.75 \mathrm{~V} \text { vs. SCE in } \mathrm{CH}_{3} \mathrm{CN}\right)^{67}$ could be feasible under specific conditions, generating pyridyl radical anion species 3 and the oxidizing $\operatorname{Ir}^{\mathrm{IV}} \mathbf{5}$. We hypothesized that $\operatorname{Ir}^{\mathrm{IV}} \mathbf{5}\left\{E_{1 / 2}{ }^{\mathrm{red}}\left[\mathrm{Ir}^{\mathrm{IV}} /\right.\right.$ $\left.\mathrm{Ir}^{\mathrm{III}}\right]=+0.77 \mathrm{~V}$ vs. SCE $\}^{66,68}$ could affect the oxidation of sodium methanesulfinate $6\left(E_{1 / 2}{ }^{\text {red }}=+0.50 \mathrm{~V}\right.$ vs. SCE) (see Supplementary Fig. 2) to form sulfonyl radical 7 and regenerate the ground-state $\mathrm{Ir}^{\mathrm{III}}$ catalyst $\mathbf{1}$. The electrophilic sulfonyl radical 7 would subsequently undergo facile radical addition to alkene to generate the nucleophilic benzylic radical 9. At this stage, we envisioned that radical-radical coupling between the transient benzylic radical 9 and the persistent pyridyl radical anion 4 would forge $\beta$-sulfonyl pyridine $10^{32-46}$. Due to the acidity of the benzylic proton and the good leaving ability of sulfone, alkyl sulfone 10 would be expected to undergo E1 elimination with the assistant of base, furnishing the final branched alkenylpyridine product 11, as well as sulfinate $\mathbf{6}$ that could be recycled.

Optimization study. Our investigation into this photoredox cascade protocol began with exposure of 1-(tert-butyl)-4-vinylbenzene 12 and 4-cyanopyridine 3 to a $90 \mathrm{~W}$ blue light-emitting diode (LED) in the presence of catalytic amounts of $\operatorname{Ir}(\mathrm{ppy})_{3}(5$ mol\%) and readily available $\mathrm{MeSO}_{2} \mathrm{Na}$ (30 mol\%) (Table 1). In the presence of a stoichiometric amount of 1,8-diazabicyclo[5.4.0] undec-7-ene (DBU) as base; pleasingly, we found that the branched vinylpyridine product could be obtained in $69 \%$ yield (entry 1). The nature of sodium sulfinates was found to have an important effect to the reaction efficiency. Generally, electronpoor aryl sulfinates, which are better leaving groups, afforded higher efficiency than electron-rich ones (entries 2-6). And, comparable yields were obtained when para-chlorophenyl sulfinate was employed as the co-catalyst (entry 4). Gratifyingly, increasing the photocatalyst loading to $5 \mathrm{~mol} \%$ provided the optimal yield of product (entry 7). Control experiments indicated that photocatalyst, sulfinate, and light were all essential to this transformation, as no desired products were observed in the absence of either photocatalyst, sulfinate, or light (entries 8-10). While conducting the reaction in the absence of DBU afforded the expected product in $18 \%$ yield, probably due to the basic condition in the presence of $\mathrm{MeSO}_{2} \mathrm{Na}$ (entry 11). Interestingly, a trace amount of $\mathrm{C} 2$-substituted product 13', which is assumed to be formed by the $S_{N} A r$ reaction of cyanopyridine with alkyl radical, was observed under the reaction conditions ${ }^{69}$.

Substrate scope. With the optimal conditions in hand, we next explored the generality of this transformation with respect to

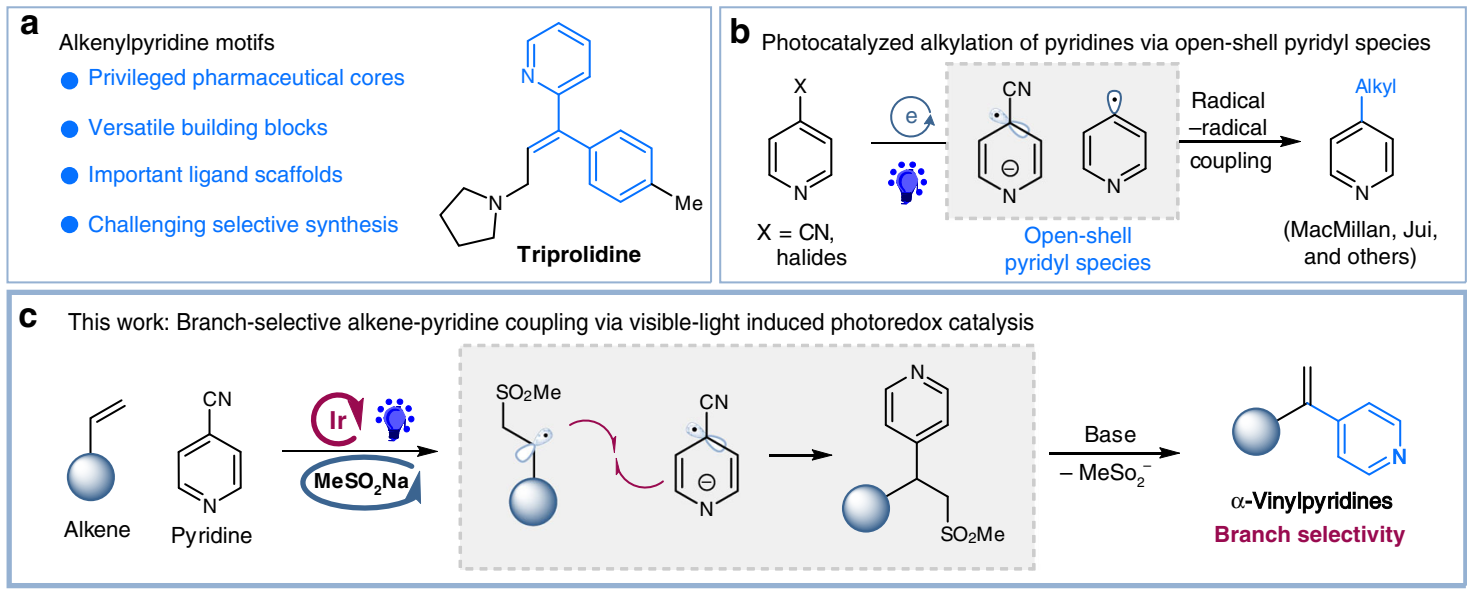

Fig. 1 Design of catalytic and branch-selective alkene-pyridine coupling via photoredox catalysis. a Importance of alkenylpyridines. b Photocatalyzed alkylations of pyridines. c Design of branch-selective alkenylation of pyridines via photoredox catalysis 


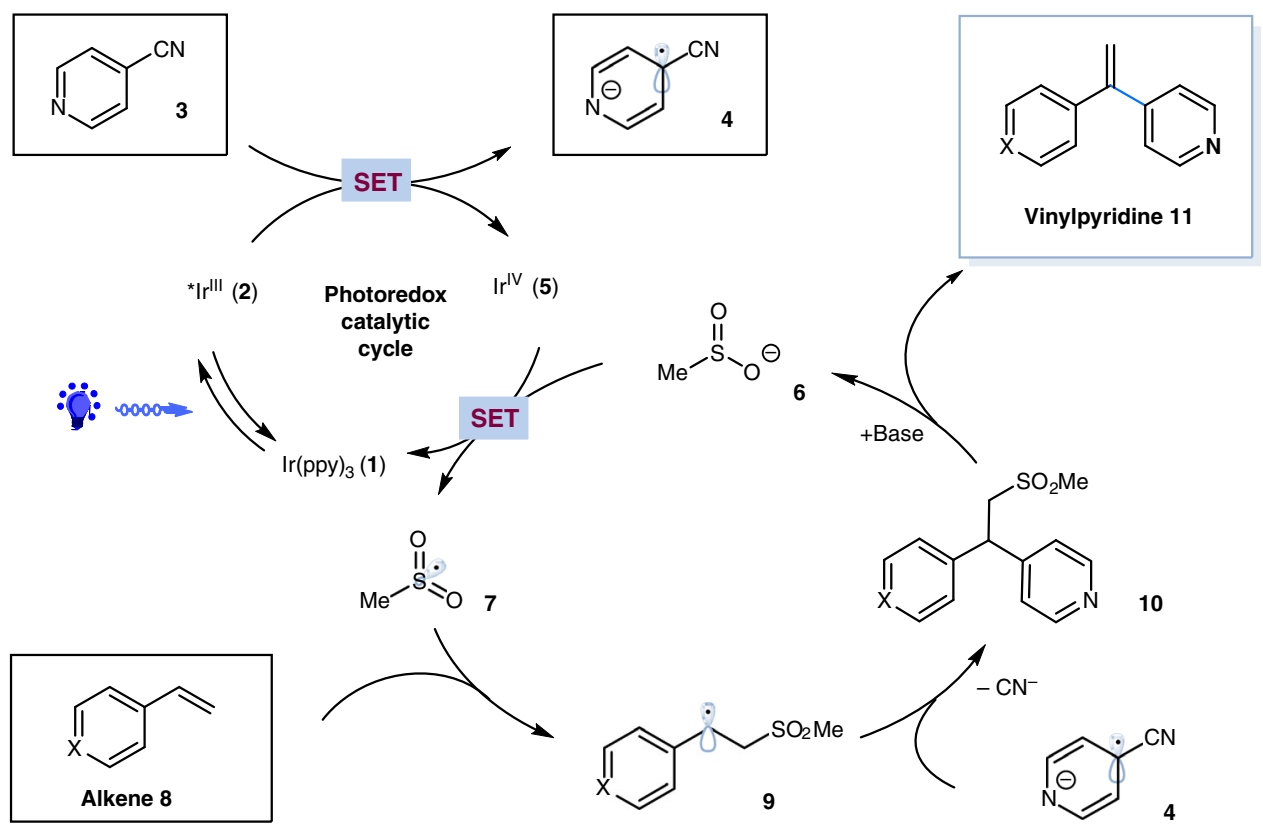

Fig. 2 Proposed mechanism. Possible reaction pathway utilizing sulfinate as a promoter

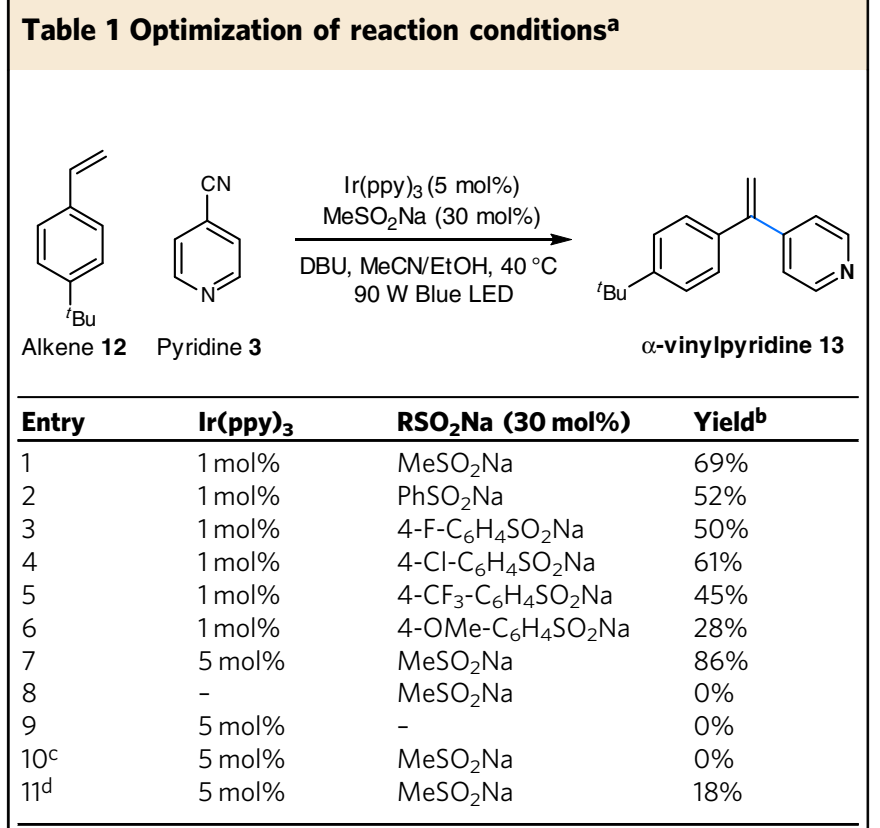

DBU 1,8-diazabicyclo[5.4.0]undec-7-ene, LED light-emitting diode, GC gas chromatography aReaction conditions: $\operatorname{Ir}(\mathrm{ppy})_{3}(5 \mathrm{~mol} \%), \mathrm{RSO}_{2} \mathrm{Na}(30 \mathrm{~mol} \%)$, styrene $(0.1 \mathrm{mmol}), 4-$ cyanopyridine (2.0 equiv.), DBU (3 equiv.), $\mathrm{MeCN} / \mathrm{EtOH}, 90 \mathrm{~W}$ blue LED, $40^{\circ} \mathrm{C}, 24 \mathrm{~h}$ byields were determined by GC using an internal standard

cPerformed in the dark

Performed in the absence of DBU

alkene component using 4-cyanopyridine as the coupling partner. As shown in Fig. 3, styrenes incorporating electron-donating and electron-withdrawing substituents readily underwent the desired radical addition/coupling/elimination cascade reactions, furnishing branched vinylpyridines in good to high yields (products 13$32,53-86 \%$ yields). The mild conditions tolerate a wide range of functional groups, including ethers, amides, esters, nitriles, chlorides, bromides, ketones, and amines (products 16-20, 2231, $53-73 \%$ yields). Moreover, ortho substituents ( $\mathrm{Me}, \mathrm{F}, \mathrm{Cl})$ on the aryl ring were compatible in this manifold, albeit with slightly diminished yields (products 30-32, 53-68\% yields). Furthermore, this catalytic protocol was applicable to other aryl and heteroaryl alkenes, in the form of naphthalene, benzofuran, thiophene, and thiazole, furnishing the corresponding products in moderate yields (products 33-36, 56-78\% yields). It should be noted that both cyclic (e.g., 1,2-dihydronaphthalene) and acyclic (e.g., trans$\beta$-methylstyrenes and benzyl ether of cinnamyl alcohol) internal alkenes were found to be viable substrates, delivering the corresponding alkenylpyridines with exclusive selectivity at the benzylic positions, respectively (products 37-40, 69-75\% yields). Finally, styrenes derived from drugs or natural products, including oxaprozin, nonivamide, hymecromone, estrone, and indomethacin, could be successfully employed to furnish the desired products in moderate to good yields (products 41-45, $48-89 \%$ yields), further highlighting the potential synthetic utility of this new protocol. Notably, piperine, a naturally occurring alkaloid, underwent selective pyridylation with synthetic useful yields (product 46, 49\% yield). Nevertheless, un-activated alkenes were ineffective under the reaction conditions, and most of alkene materials remained, probably due to their weaker electrophilic nature.

We next sought to explore the scope regarding cyanopyridines (Fig. 4). Nevertheless, we found that only 4-cyanopyridines with alkyl and/or aryl substituents at the 2-positions underwent the desired couplings with moderate efficiency under the standard conditions (products 47-48, and 50, with yields around 50\%). Pleasingly, employing a stoichiometric amount of 4-chlorophenyl sulfinate as the radical precursor and $\mathrm{NH}_{4} \mathrm{Cl}$ as the additive could improve the reaction efficiency. Under the modified conditions, a wide range of cyanopyridines could be successfully employed, furnishing the desired $\alpha$-vinylpyridines in moderate to good yields (products $\mathbf{4 7 - 5 8}, 71-86 \%$ yields). Notably, halogen atoms remained intact under the photocatalytic conditions, offering useful handles for further synthetic manipulations (products 53-56, 71-72\% yields). Interestingly, 3,4-dicyanopyridine underwent selective coupling at C4 (product 58, 86\% yield), while 2,4-dicyanopyridine afforded a mixture of regioisomeric products (product 51, 81\% yield, r.r.=1.7:1). Ortho substituents on the pyridines have no deleterious effect to the coupling/elimination 


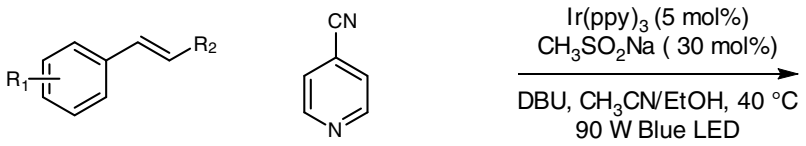

Alkene

Cyanopyridine<smiles>C=C(c1ccccc1)c1ccncc1</smiles>

$1478 \%$ yield<smiles>C=C(c1ccncc1)c1ccc(OC)cc1</smiles>

$1870 \%$ yield<smiles>C=C(c1ccncc1)c1cccc(C(F)(F)F)c1</smiles>

$2360 \%$ yield $^{a}$<smiles>C=C(c1ccncc1)c1cccc(Cl)c1</smiles>

$2969 \%$ yield<smiles>C=C(c1ccncc1)c1ccsc1</smiles>

35 63\% yield<smiles>C=C(c1ccncc1)c1cccc(C)c1</smiles>

$1571 \%$ yield<smiles>C=C(c1ccncc1)c1ccc(Br)cc1</smiles>

$1386 \%$ yield<smiles></smiles>

Branch-selective alkenylpyridine

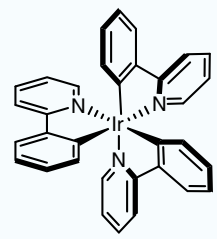<smiles>C=C(c1ccncc1)c1ccc2c(c1)OCCO2</smiles>

$1670 \%$ yield<smiles>C=C(c1ccncc1)c1ccc(NC(=O)c2ccccc2)cc1</smiles>

$1760 \%$ yield<smiles>C=C(c1ccncc1)c1ccc(Oc2ccccc2)cc1</smiles>

19 67\% yield<smiles>C=C(c1ccncc1)c1ccc(N)cc1</smiles>

$2062 \%$ yield $^{\mathrm{a}}$<smiles>C=C(c1ccncc1)c1ccc(-c2ccccc2)cc1</smiles>

$2182 \%$ yield<smiles>C=C(c1ccncc1)c1ccc(Br)cc1</smiles>

$2771 \%$ yield<smiles>C=C(c1ccncc1)c1ccc2ccccc2c1</smiles>

$3378 \%$ yield $^{b}$<smiles>CC=C(c1ccncc1)c1ccc(Br)cc1</smiles>

$38 \mathrm{X}=\mathrm{H}, 69 \%(Z: E=1: 1)^{\mathrm{b}, \mathrm{c}}$ $39 \mathrm{X}=\mathrm{OMe}, 74 \%(Z: E=7: 3)^{\mathrm{b}, \mathrm{c}}$<smiles>C=C(c1ccncc1)c1ccc(-c2ccc(C#N)cc2)cc1</smiles>

22 67\% yield<smiles>C=C(c1ccncc1)c1ccc(OC)c(Br)c1</smiles>

$2873 \%$ yield<smiles>C=C(c1ccncc1)c1ccc2occc2c1</smiles>

34 76\% yield<smiles>O=C(O)c1ccccc1</smiles>

$4058 \%$ yield $^{a}$<smiles>C=C(c1ccncc1)c1ccc(NC(=O)CCc2nc(-c3ccccc3)c(-c3ccccc3)o2)cc1</smiles>

Oxaprozin derivative $4189 \%$ yield $^{a}$

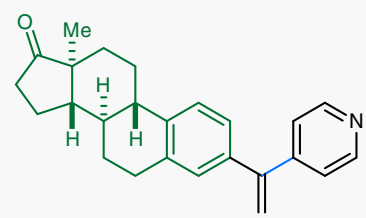

Estrone derivative $4457 \%$ yield $^{b}$<smiles>C=C(c1ccncc1)c1ccc(CNC(=O)CCCCCC)cc1OC</smiles>

Nonivamide derivative $4248 \%$ yield $^{\mathrm{b}}$

$\mathrm{MeO}$<smiles>C=C(c1ccncc1)c1ccc(NC(=O)Cc2c(C)[nH]c3cc(O)ccc23)cc1</smiles>
$4586 \%$ yield $^{\mathrm{a}}$<smiles>C=C(c1ccncc1)c1ccc2c([N+](=O)[O-])cc(=O)oc2c1</smiles>

Hymecromone derivative $4356 \%$ yield $^{\mathrm{a}}$

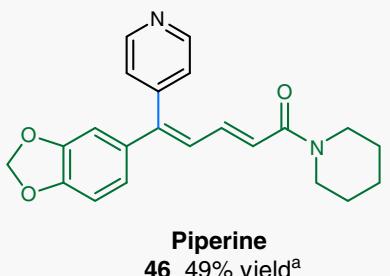

Fig. 3 Substrate scope of olefins. Reaction conditions: $\operatorname{Ir}(\mathrm{ppy})_{3}(5 \mathrm{~mol} \%), \mathrm{MeSO}_{2} \mathrm{Na}(30 \mathrm{~mol} \%$ ), alkene (0. mmol), 4-cyanopyridine (2.0 equiv.), DBU (3 equiv.), $\mathrm{MeCN} / \mathrm{EtOH}(1: 1), 90 \mathrm{~W}$ blue light-emitting diode (LED), $40{ }^{\circ} \mathrm{C}, 24 \mathrm{~h}$. All cited yields are isolated yields. ${ }^{\mathrm{E}}$ Employed with $4-\mathrm{Cl}-\mathrm{C}_{6} \mathrm{H}_{4} \mathrm{SO}_{2} \mathrm{Na}(1.0$ equiv). bemployed with $4-\mathrm{Cl}_{-} \mathrm{C}_{6} \mathrm{H}_{4} \mathrm{SO}_{2} \mathrm{Na}$ (0.5 equiv.). ${ }^{c}$ The ratio was determined by proton nuclear magnetic resonance ( ${ }^{1} \mathrm{H}$ NMR) analysis

efficiency (products 56-58, 71-86\% yields). Moreover, unprotected azaindole nitrile also was a viable substrate (product $\mathbf{5 8}$, $73 \%$ yield). Notably, 1-cyanoisoquinoline and 2-cyanopyridines also underwent the selective alkenylation smoothly, delivering the corresponding vinylquinoline and vinylpyridines with moderate efficiency (products 13', 60-63, 69-85\% yields). Pleasingly, performing the photocatalytic reaction on a $5 \mathrm{mmol}$ scale afforded product 63 with comparable efficiency (see Supplementary Fig. 1 for details).

To demonstrate the synthetic application of this sequential photoredox protocol, we have accomplished the expedient synthesis of Triprolidine, a top-selling antihistamine that used for allergies ${ }^{70,71}$. As shown in Fig. 5a, Pd-catalyzed amination of commercially available allylic 4-methylcinnamic alcohol 64 gave 
<smiles>C=Cc1ccc(Br)cc1</smiles><smiles></smiles>

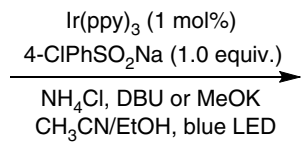<smiles>C=C(c1ccncc1)c1ccc(Br)cc1</smiles><smiles>C=C(c1ccccc1)c1ccnc([N+](=O)[O-])c1</smiles>

$4778 \%$ yield<smiles>C=C(c1ccccc1)c1ccnc(Cl)c1</smiles>

$5372 \%$ yield<smiles>C=C(c1ccccc1)c1ccnc2[nH]ccc12</smiles>

59 73\% yield<smiles>C=C(c1ccccc1)c1cc([N+](=O)[O-])nc([N+](=O)[O-])c1</smiles>

$4874 \%$ yield<smiles>C=C(c1ccccc1)c1ccnc(F)c1</smiles>

$5471 \%$ yield<smiles>C=C(c1ccccc1)c1nccc2ccccc12</smiles>

$6085 \%$ yield<smiles>C=C(c1ccccc1)c1ccnc(OC)c1</smiles>

$4984 \%$ yield<smiles>C=C(c1ccccc1)c1ccnc(Br)c1</smiles>

$5571 \%$ yield<smiles>C=C(c1ccccc1)c1ccccn1</smiles>

$13^{\prime} 75 \%$ yield<smiles>C=C(c1ccccc1)c1ccnc(-c2ccccc2)c1</smiles>

$5086 \%$ yield<smiles>C=C(c1ccccc1)c1ccncc1Cl</smiles>

$5671 \%$ yield<smiles>C=C(c1ccccc1)c1cc(C(F)(F)F)ccn1</smiles>

$6179 \%$ yield<smiles>C=C(c1ccccc1)c1ccnc(C#N)c1</smiles>

$5181 \%$ yield $(\text { r.r. }=1.7: 1)^{a}$<smiles>C=C(c1ccccc1)c1ccncc1[N+](=O)[O-]</smiles>

$5780 \%$ yield<smiles>C=C(c1ccccn1)c1cc(F)ccn1</smiles>

$6280 \%$ yield<smiles>C=C(c1ccccc1)c1ccnc(CF)c1</smiles>

$5274 \%$ yield<smiles>C=C(c1ccccc1)c1ccncc1C#N</smiles>

$5886 \%$ yield<smiles>COc1ccccn1</smiles>

$6369 \%$ yield

(5 mmol: $66 \%$ yield) ${ }^{b}$

Fig. 4 Substrate scope of pyridines. Reaction conditions: $\operatorname{lr}(\mathrm{ppy})_{3}(1 \mathrm{~mol} \%), 4-\mathrm{Cl}-\mathrm{PhSO}_{2} \mathrm{Na}$ (1.0 equiv.), styrene (0.2 mmol), cyanopyridine (2.0 equiv.), $\mathrm{NH}_{4} \mathrm{Cl}$ (2 equiv.), base ( 6 equiv.), $\mathrm{MeCN} / \mathrm{EtOH}, 90 \mathrm{~W}$ blue light-emitting diode (LED, $40^{\circ} \mathrm{C}, 2 \mathrm{~h}$. All cited yields are isolated yields. aThe ratio was determined by ${ }^{1} \mathrm{H}$ NMR analysis. beaction performed on a $5 \mathrm{mmol}$ scale. see Supplementary Fig. 1 for details. Ar $=4$-tert-butylphenyl

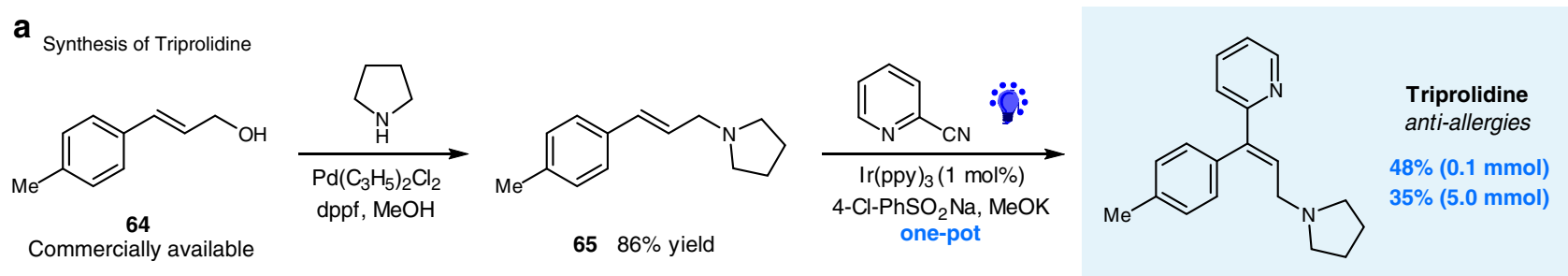

b Synthesis of Pheniramine precursor
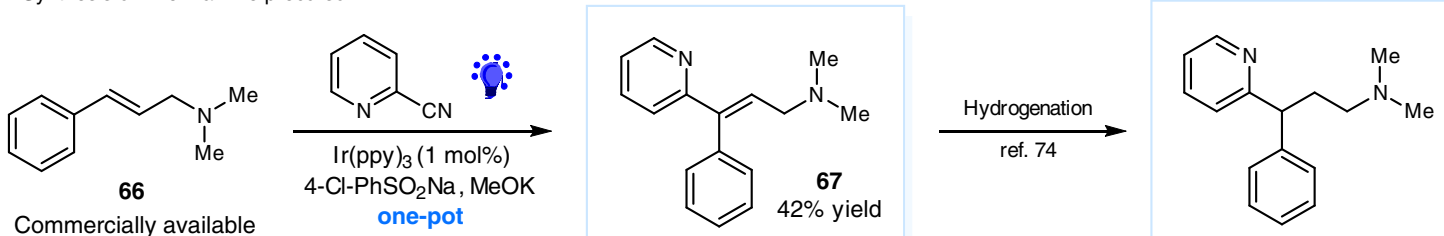

Pheniramine anti-allergies

Fig. 5 Synthesis of Triprolidine. a One-pot synthesis of Triprolidine via photoredox catalysis. b Synthesis of pheniramine precursor

the allylic amine precursor 65 in $86 \%$ yield $^{72}$. Reaction of $\mathbf{6 5}$ with simple 2-cyanopyridine under our photocatalytic conditions directly delivered Triprolidine in a simple and one-pot operation with a synthetic useful yield ( $48 \%$ yield). Notably, a $5 \mathrm{mmol} \mathrm{scale}$ synthesis of Triprolidine was performed, albeit with slightly decreased efficiency ( $35 \%$ yield). Furthermore, subjection of allylic amine 65 to the photocatalytic condition, yielding the desired pyridyl product $\mathbf{6 6}$, a precursor for drug pheniramine ${ }^{73}$ through one-step hydrogenation ${ }^{74}$, with $42 \%$ yield (Fig. $5 b$ ).

Mechanistic studies. To further probe the mechanism proposal of this photocatalytic reaction, we performed Stern-Volmer fluorescence quenching studies. As shown in Supplementary Fig. 3, only cyanopyridine was found to quench the excited state of ${ }^{\star} \operatorname{Ir}(\mathrm{ppy})_{3}$, while no significant quenching was observed in the presence of sulfinate or DBU, lending support for our proposed oxidative quenching pathway (Fig. 2). Next, investigation of the intermediacy of a sulfonyl radical was conducted (Fig. 6). Reaction of vinylcyclopropane 68 with $\mathrm{MeSO}_{2} \mathrm{Na}$ and 4-cyanopyridine in the presence of $\operatorname{Ir}(\mathrm{ppy})_{3}$ and DBU afforded product 69, which could be formed through a sequential sulfonyl addition/ring opening/radical coupling protocol (Fig. 6a). Furthermore, the reaction of styrene and 4-chlorophenyl sulfinate, in the absence of DBU, gave $24 \%$ of the desired vinylpyridine product $\mathbf{1 6}$ as well as $65 \%$ of isolable $\beta$-sulfonyl pyridine 70. As expected, treatment of 70 with DBU gave vinylpyridine 16 in $94 \%$ yield (Fig. 6b). These results further supported the intermediacy of a sulfonyl radical species in the transformation. Regarding the coupling step for forging the $\mathrm{C}$-pyridine bond, nevertheless, we cannot rule out alternative pathway that proceeds via $S_{N} A r$ reaction of pyridine with alkyl radical 9, particularly with the observation of a trace amount of C2-substituted product (see Supplementary Fig. 4 for this alternative pathway). 
a Radical clock experiment<smiles>C=C(c1ccccc1)C1CC1c1ccccc1</smiles>

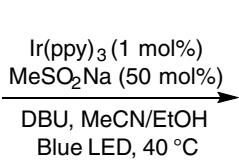

3

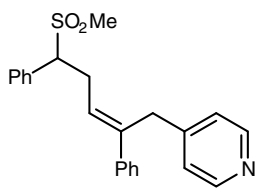

$6934 \%$ yield
68

b Isolation of alkylsulfone intermediate<smiles>C=Cc1ccc(C(C)(C)C)cc1</smiles>

$$
\begin{gathered}
\underset{\mathrm{Ir}(\mathrm{ppy})_{3}(1 \mathrm{~mol} \%)}{4-\mathrm{Cl}-\mathrm{PhSO}_{2} \mathrm{Na}} \\
\stackrel{(1.5 \text { equiv. })}{\longrightarrow} \\
\underset{\mathrm{MeCN} / \mathrm{EtOH}, 40{ }^{\circ} \mathrm{C}}{\text { Blue LED }} \\
\text { w/o DBU }
\end{gathered}
$$

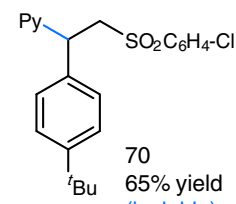
(isolable)<smiles>C=C(Br)c1ccc(C)cc1</smiles>
${ }^{t} \mathrm{Bu} \quad 24 \%$ yield 9 $94 \%$ yield $\mathrm{DBU}, \mathrm{MeCN} / \mathrm{EtOH}$

Fig. 6 Mechanistic studies. a Radical clock experiment. b Isolation of alkyl sulfone intermediate

\section{Discussion}

In conclusion, we have developed an efficient strategy for branchselective, formal alkene-pyridines cross-coupling via sulfinateassisted photoredox catalysis. This versatile protocol utilizes a sequential radical addition, radical coupling, and $\beta$-elimination protocol, allowing for the construction of branched alkenylpyridines from simple starting material under mild conditions. Notably, an expedient and an operationally simple, one-pot synthesis of Troprilidine has been successfully achieved through this photocatalytic manifold.

\section{Methods}

General procedure for the branch-selective alkenylpyridylation reaction. To a flame-dried $20 \mathrm{~mL}$ reaction vial was charged with $\operatorname{Ir}(\mathrm{ppy})_{3}(1.0 \mathrm{~mol} \%), \mathrm{MeSO}_{2} \mathrm{Na}$ (30 mol\%), 4-cyanopyridine ( $0.4 \mathrm{mmol}, 2.0$ equiv.), and a magnetic stir bar. $\mathrm{MeCN} /$ $\mathrm{EtOH}(1: 1 \mathrm{v} / \mathrm{v})[0.02 \mathrm{M}]$ was added, and the vial was capped. The reaction mixture was degassed by nitrogen sparging for $15 \mathrm{~min}$, followed by the addition of alkenes $(0.2 \mathrm{mmol}, 1.0$ equiv.) and DBU ( $0.6 \mathrm{mmol}, 3.0$ equiv.). The reaction mixture was then irradiated with a $90 \mathrm{~W}$ blue LED for $24 \mathrm{~h}$ at $40^{\circ} \mathrm{C}$. The reaction mixture was concentrated in vacuo and then quenched with water, extracted with ethyl acetate. The combined organic layers were dried with $\mathrm{MgSO}_{4}$, filtered, and concentrated in vacuo. The crude material was purified by flash chromatography to afford the products. See Supplementary Methods for further experimental details.

\section{Data availability}

The authors declare that all the data supporting the findings of this work are available within the article and its Supplementary Information files, or from the corresponding author upon request.

Received: 7 October 2018 Accepted: 23 January 2019

Published online: 14 February 2019

\section{References}

1. Li, J. J. Heterocyclic Chemistry in Drug Discovery (Wiley, New York, 2013).

2. Vitaku, E., Smith, D. T. \& Njardarson, J. T. Analysis of the structural diversity, substitution patterns, and frequency of nitrogen heterocycles among U.S. FDA approved pharmaceuticals. J. Med. Chem. 57, 10257-10274 (2014).

3. Jung, M. E. in Comprehensive Organic Synthesis, Vol. 4 (ed. Trost, B. M.) 10 and 77 (Pergamon Press, Oxford, 1991).

4. Klumpp, D. A. Conjugate additions to vinyl-substituted aromatic $N$ heterocycles. Synlett 23, 1590-1604 (2012).

5. Chelucci, G. Metal-complexes of optically active amino- and imino-based pyridine ligands in asymmetric catalysis. Coord. Chem. Rev. 257, 1887-1932 (2013).

6. Vorbrüggen, H. \& Krolikiewcz, K. Conversion of heterocyclic n-oxides into aalkylated heterocycles trimethylsilanol as leaving group-IV. Tetrahedron Lett. 24, 889-890 (1983).

7. Comins, D. \& Mantlo, N. Regiospecific.alpha.-alkylation of 4-chloro(bromo) pyridine. J. Org. Chem. 50, 4410-4411 (1985).

8. Zhang, G., Irrgang, T., Dietel, T., Kallmeier, F. \& Kempe, R. Manganesecatalyzed dehydrogenative alkylation or $\alpha$-olefination of alkyl-substituted nheteroarenes with alcohols. Angew. Chem. Int. Ed. 57, 9131-9135 (2018).

9. Kanyiva, K. S., Nakao, Y. \& Hiyama, T. Nickel-catalyzed addition of pyridineN-oxides across alkynes. Angew. Chem. Int. Ed. 46, 8872-8874 (2007).

10. Huckins, J. R., Bercot, E. A., Thiel, O. R., Hwang, T.-L. \& Bio, M. M. Rh(III)catalyzed $\mathrm{C}-\mathrm{H}$ activation and double directing group strategy for the regioselective synthesis of naphthyridinones. J. Am. Chem. Soc. 135, 14492-14495 (2013).

11. Mizoroki, T., Mori, K. \& Ozaki, A. Arylation of olefin with aryl iodide catalyzed by palladium. Bull. Chem. Soc. Jpn. 44, 581-581 (1971).

12. Heck, R. F. \& Nolley, J. P. Palladium-catalyzed vinylic hydrogen substitution reactions with aryl, benzyl, and styryl halides. J. Org. Chem. 37, 2320-2322 (1972).

13. Beletskaya, I. P. \& Cheprakov, A. V. The Heck reaction as a sharpening stone of palladium catalysis. Chem. Rev. 100, 3009-3066 (2000).

14. Nakao, Y., Kanyiva, K. S. \& Hiyama, T. A strategy for $\mathrm{C}-\mathrm{H}$ activation of pyridines: direct C-2 selective alkenylation of pyridines by Nickel/Lewis Acid catalysis. J. Am. Chem. Soc. 130, 2448-2449 (2008).

15. Tsai, C.-C. et al. Bimetallic nickel aluminun mediated para-selective alkenylation of pyridine: direct observation of $\eta 2, \eta 1$-pyridine $\mathrm{Ni}(0)-\mathrm{Al}(\mathrm{III})$ intermediates prior to $\mathrm{C}-\mathrm{H}$ bond activation. J. Am. Chem. Soc. 132, 11887-11889 (2010).

16. Ye, M., Gao, G.-L. \& Yu, J.-Q. Ligand-promoted C-3 selective C-H olefination of pyridines with Pd catalysts. J. Am. Chem. Soc. 133, 6964-6967 (2011).

17. Goriya, Y. \& Ramana, C. V. Ruthenium-catalyzed C6-propenylation reactions of substituted pyridine derivatives: directed and direct $\mathrm{C}-\mathrm{H}$ activation. Chem. Eur. J. 18, 13288-13292 (2012).

18. Wen, P. et al. Palladium-catalyzed C-2 selective C-H olefination of pyridines. Adv. Syn. Catal. 354, 2135-2140 (2012).

19. Zhou, J., Li, B., Hu, F. \& Shi, B.-F. Rhodium(III)-catalyzed oxidative olefination of pyridines and quinolines: multigram-scale synthesis of naphthyridinones. Org. Lett. 15, 3460-3463 (2013).

20. Wu, J., Cui, X., Chen, L., Jiang, G. \& Wu, Y. Palladium-catalyzed alkenylation of quinoline- $\mathrm{N}$-oxides via $\mathrm{C}-\mathrm{H}$ activation under external-oxidant-free conditions. J. Am. Chem. Soc. 131, 13888-13889 (2009).

21. Roudesly, F., Veiros, L. F., Oble, J. \& Poli, G. Pd-catalyzed direct C-H alkenylation and allylation of azine N-oxides. Org. Lett. 20, 2346-2350 (2018).

22. Miller, J. A. \& Dankwardt, J. W. Nickel catalyzed cross-coupling of modified alkyl and alkenyl Grignard reagents with aryl- and heteroaryl nitriles: activation of the C-CN bond. Tetrahedron Lett. 44, 1907-1910 (2003).

23. Miller, J. A., Dankwardt, J. W. \& Penney, J. M. Nickel catalyzed cross-coupling and amination reactions of aryl nitriles. Synthesis 2003, 1643-1648 (2003).

24. Mo, J., Xu, L. \& Xiao, J. Ionic liquid-promoted, highly regioselective Heck arylation of electron-rich olefins by aryl halides. J. Am. Chem. Soc. 127, 751-760 (2005).

25. Mo, J. \& Xiao, J. The Heck reaction of electron-rich olefins with regiocontrol by hydrogen-bond donors. Angew. Chem. Int. Ed. 45, 4152-4157 (2006).

26. Qin, L., Ren, X., Lu, Y., Li, Y. \& Zhou, J. Intermolecular Mizoroki-Heck reaction of aliphatic olefins with high selectivity for substitution at the internal position. Angew. Chem. Int. Ed. 51, 5915-5919 (2012).

27. Stephenson, C. R. J., Yoon, T. P. \& MacMillan, D. W. C. Visible Light Photocatalysis in Organic Chemistry (Wiley-VCH, New York, 2018).

28. Prier, C. K., Rankic, D. A. \& MacMillan, D. W. C. Visible light photoredox catalysis with transition metal complexes: applications in organic synthesis. Chem. Rev. 113, 5322-5363 (2013).

29. Romero, N. A. \& Nicewicz, D. A. Organic photoredox catalysis. Chem. Rev. 116, 10075-10166 (2016).

30. Chen, J.-R., Hu, X.-Q., Lu, L.-Q. \& Xiao, W.-J. Exploration of visible-light photocatalysis in heterocycle synthesis and functionalization: reaction design and beyond. Acc. Chem. Res. 49, 1911-1923 (2016).

31. Matsui, J. K., Lang, S. B., Heitz, D. R. \& Molander, G. A. Photoredox-mediated routes to radicals: the value of catalytic radical generation in synthetic methods development. ACS Catal. 7, 2563-2575 (2017).

32. Mangion, D. \& Arnold, D. R. Photochemical nucleophile-olefin combination, aromatic substitution reaction. its synthetic development and mechanistic exploration. Acc. Chem. Res. 35, 297-304 (2002).

33. McNally, A., Prier, C. K. \& MacMillan, D. W. C. Discovery of an a-amino $\mathrm{C}-\mathrm{H}$ arylation reaction using the strategy of accelerated serendipity. Science 334, 1114 (2011).

34. Zuo, Z. \& MacMillan, D. W. C. Decarboxylative arylation of $\alpha$-amino acids via photoredox catalysis: a one-step conversion of biomass to drug pharmacophore. J. Am. Chem. Soc. 136, 5257-5260 (2014).

35. Qvortrup, K., Rankic, D. A. \& MacMillan, D. W. C. A general strategy for organocatalytic activation of $\mathrm{C}-\mathrm{H}$ bonds via photoredox catalysis: direct arylation of benzylic ethers. J. Am. Chem. Soc. 136, 626-629 (2014). 
36. Cuthbertson, J. D. \& MacMillan, D. W. C. The direct arylation of allylic sp3 C$\mathrm{H}$ bonds via organic and photoredox catalysis. Nature 519, 74-77 (2015)

37. Lima, F. et al. Visible light activation of boronic esters enables efficient photoredox $\mathrm{C}(\mathrm{sp}(2))-\mathrm{C}(\mathrm{sp}(3))$ cross-couplings in flow. Angew. Chem. Int. Ed. 55, 14085-14089 (2016).

38. Lipp, B., Nauth, A. M. \& Opatz, T. Transition-metal-free decarboxylative photoredox coupling of carboxylic acids and alcohols with aromatic nitriles. J. Org. Chem. 81, 6875-6882 (2016).

39. Boyington, A. J., Riu, M.-L. Y. \& Jui, N. T. Anti-Markovnikov hydroarylation of unactivated olefins via pyridyl radical intermediates. J. Am. Chem. Soc. 139, 6582-6585 (2017).

40. Aycock, R. A., Wang, H. \& Jui, N. T. A mild catalytic system for radical conjugate addition of nitrogen heterocycles. Chem. Sci. 8, 3121-3125 (2017).

41. Aycock, R. A., Vogt, D. B. \& Jui, N. T. A practical and scalable system for heteroaryl amino acid synthesis. Chem. Sci. 8, 7998-8003 (2017).

42. Deng, Y., Liu, Q. \& Smith, A. B. 3rd Oxidative [1,2]-Brook rearrangements exploiting single-electron transfer: photoredox-catalyzed alkylations and arylations. J. Am. Chem. Soc. 139, 9487-9490 (2017).

43. Buzzetti, L., Prieto, A., Roy, S. R. \& Melchiorre, P. Radical-based C-C bondforming processes enabled by the photoexcitation of 4-alkyl-1,4dihydropyridines. Angew. Chem. Int. Ed. 56, 15039-15043 (2017)

44. Zhou, W., Miura, T. \& Murakami, M. Photocatalyzed ortho-alkylation of pyridine $\mathrm{N}$-oxides through alkene cleavage. Angew. Chem. Int. Ed. 57, 5139-5142 (2018).

45. Seath, C. P., . \& Vogt, D. B. \& Xu, Z. \& Boyington, A. J. \& Jui, N. T. Radical hydroarylation of functionalized olefins and mechanistic investigation of photocatalytic pyridyl radical reactions. J. Am. Chem. Soc. 45, 15525-15534 (2018).

46. Chen, D. et al. Metal-free, intermolecular carbopyridylation of alkenes via visible-light-induced reductive radical coupling. Chem. Sci. 9, 9012-9017 (2018).

47. Meyer, A. U., Jäger, S., Prasad Hari, D. \& König, B. Visible light-mediated metal-free synthesis of vinyl sulfones from aryl sulfinates. Adv. Synth. Catal. 357, 2050-2054 (2015).

48. Meyer, A. U., Straková, K., Slanina, T. \& König, B. Eosin Y (EY) photoredoxcatalyzed sulfonylation of alkenes: scope and mechanism. Chem. Eur. J. 22, 8694-8699 (2016).

49. Zhang, G. et al. Visible-light induced oxidant-free oxidative cross-coupling for constructing allylic sulfones from olefins and sulfinic acids. Chem. Commun. 52, 10407-10410 (2016).

50. Gualandi, A. et al. Photocatalytic radical alkylation of electrophilic olefins by benzylic and alkylic zinc-sulfinates. ACS Catal. 7, 5357-5362 (2017).

51. Knauber, T. et al. Ru/Ni dual catalytic desulfinative photoredox Csp2-Csp3 cross-coupling of alkyl sulfinate salts and aryl halides. Org. Lett. 19, 6566-6569 (2017).

52. Meyer, A. U., Lau, V. W.-h, König, B. \& Lotsch, B. V. Photocatalytic oxidation of sulfinates to vinyl sulfones with cyanamide-functionalised carbon nitride. Eur. J. Org. Chem. 2017, 2179-2185 (2017).

53. Wang, H. et al. Markovnikov-selective radical addition of S-nucleophiles to terminal alkynes through a photoredox process. Angew. Chem. Int. Ed. 56, 595-599 (2017).

54. Cabrera-Afonso, M. J. et al. Engaging sulfinate salts via $\mathrm{Ni} /$ photoredox dual catalysis enables facile Csp2-SO2R coupling. Chem. Sci. 9, 3186-3191 (2018).

55. Hasegawa, E. et al. Visible light and hydroxynaphthylbenzimidazoline promoted transition-metal-catalyst-free desulfonylation of $\mathrm{N}$-sulfonylamides and N-sulfonylamines. J. Org. Chem. 83, 10813-10825 (2018).

56. Johnson, T. C. et al. Direct sulfonylation of anilines mediated by visible light. Chem. Sci. 9, 629-633 (2018).

57. Li, Y., Miao, T., Li, P. \& Wang, L. Photo-driven synthesis of C6polyfunctionalized phenanthridines from three-component reactions of isocyanides, alkynes, and sulfinic acids by electron donor-acceptor complex. Org. Lett. 20, 1735-1739 (2018).

58. Liu, N.-W., Hofman, K., Herbert, A. \& Manolikakes, G. Visible-light photoredox/nickel dual catalysis for the cross-coupling of sulfinic acid salts with aryl iodides. Org. Lett. 20, 760-763 (2018).

59. Pirenne, V. et al. Eosin-mediated alkylsulfonyl cyanation of olefins. Org. Lett. 20, 4521-4525 (2018).

60. Rohokale, R. S., Tambe, S. D. \& Kshirsagar, U. A. Eosin Y photoredox catalyzed net redox neutral reaction for regiospecific annulation to 3 sulfonylindoles via anion oxidation of sodium sulfinate salts. Org. Biol. Chem. 16, 536-540 (2018).

61. Sun, D. \& Zhang, R. Transition-metal-free, visible-light-induced oxidative cross-coupling for constructing $\beta$-acetylamino acrylosulfones from sodium sulfinates and enamides. Org. Chem. Front. 5, 92-97 (2018).

62. Yue, H., Zhu, C. \& Rueping, M. Cross-coupling of sodium sulfinates with aryl, heteroaryl, and vinyl halides by nickel/photoredox dual catalysis. Angew. Chem. Int. Ed. 57, 1371-1375 (2018).
63. Wallace, T. J., Hofmann, J. E. \& Schriesheim, A. Base-catalyzed elimination studies on sulfones, sulfoxides, sulfides, disulfides, and mercaptans in dimethyl sulfoxide. J. Am. Chem. Soc. 85, 2739-2743 (1963).

64. Baker-Glenn, C. A. G., Barrett, A. G. M., Gray, A. A., Procopiou, P. A. \& Ruston, M. Alkene synthesis: elimination of arenesulfinic acid from alkyl aryl sulfones using potassium trimethylsilanolate as base. Tetrahedron Lett. 46, 7427-7430 (2005).

65. Yao, C.-Z., Li, Q.-Q., Wang, M.-M., Ning, X.-S. \& Kang, Y.-B. (E)-Specific direct Julia-olefination of aryl alcohols without extra reducing agents promoted by bases. Chem. Commun. 51, 7729-7732 (2015).

66. Dixon, I. M. et al. A family of luminescent coordination compounds: iridium (III) polyimine complexes. Chem. Soc. Rev. 29, 385-391 (2000).

67. Andrieux, C. P., Gelis, L., Medebielle, M., Pinson, J. \& Saveant, J. M. Outersphere dissociative electron transfer to organic molecules: a source of radicals or carbanions? Direct and indirect electrochemistry of perfluoroalkyl bromides and iodides. J. Am. Chem. Soc. 112, 3509-3520 (1990).

68. Flamigni, L., Barbieri, A., Sabatini, C., Ventura, B. \& Barigelletti, F. Photochemistry and photophysics of coordination compounds: iridium. Top. Curr. Chem. 281, 143-203 (2007)

69. Traynham, J. G. Ipso substitution in free-radical aromatic substitution reactions. Chem. Rev. 79, 323-330 (1979).

70. Monti, J. M. \& Monti, D. Histamine $\mathrm{H} 1$ receptor antagonists in the treatment of insomnia. Cns. Drugs 13, 87-96 (2000).

71. Rao, G. V., Swamy, B. N., Kumar, P. H. \& Reddy, G. C. A simple and convenient synthesis of Triprolidine. Org. Prep. Proced. Int. 41, 168-171 (2009).

72. Jing, J. et al. Direct use of allylic alcohols and allylic amines in palladium-catalyzed allylic amination. Chem. Commun. 53, 5151-5154 (2017).

73. Karaman, K. et al. Effects of dexamethasone and pheniramine hydrogen maleate on stress response in patients undergoing elective laparoscopic cholecystectomy. Am. J. Surg. 205, 213-219 (2013).

74. Botteghi, C., Del Ponte, G. \& Marchetti, C. Synthesis of an optically active pheniramine by enantioselective hydrogenation catalysed by BINAPruthenium (II) complexes. J. Mol. Catal. 83, L1-L4 (1993).

\section{Acknowledgements}

We thank the National Natural Science Foundation of China (21702029), and the "Thousand Plan" Youth program, and the Shanghai Sailing Program (17YF1400100) for financial support.

\section{Author contributions}

L.C. conceived and designed the project. L.C. and S.Z. designed the experiments. S.Z., J.Q., F.W., and H.L. performed the experiments and analyzed the data. L.C. prepared the manuscript.

\section{Additional information}

Supplementary Information accompanies this paper at https://doi.org/10.1038/s41467 019-08669-1.

Competing interests: The authors declare no competing interests.

Reprints and permission information is available online at http://npg.nature.com/ reprintsandpermissions/

Journal peer review information: Nature Communications thanks the anonymous reviewers for their contribution to the peer review of this work.

Publisher's note: Springer Nature remains neutral with regard to jurisdictional claims in published maps and institutional affiliations.

Open Access This article is licensed under a Creative Commons Attribution 4.0 International License, which permits use, sharing, adaptation, distribution and reproduction in any medium or format, as long as you give appropriate credit to the original author(s) and the source, provide a link to the Creative Commons license, and indicate if changes were made. The images or other third party material in this article are included in the article's Creative Commons license, unless indicated otherwise in a credit line to the material. If material is not included in the article's Creative Commons license and your intended use is not permitted by statutory regulation or exceeds the permitted use, you will need to obtain permission directly from the copyright holder. To view a copy of this license, visit http://creativecommons.org/ licenses/by/4.0/

(C) The Author(s) 2019 